Dermatology 2018;234:226-228

DOI: $10.1159 / 000492468$

\section{Tattoos and Penalty Success at the FIFA World Cup 2018}

Simon M. Müller ${ }^{\mathrm{a}}$ Samuel Hogg ${ }^{\mathrm{b}}$ Peter Itin ${ }^{\mathrm{a}}$

a Department of Dermatology, University Hospital Basel, Basel, Switzerland; ${ }^{b}$ Dermatology Centre, Manchester Academic Health Science Centre, University of Manchester, Manchester, UK

\section{Keywords}

Tattoo $\cdot$ Personality traits $\cdot$ Penalties $\cdot$ Soccer $\cdot$ FIFA World Cup

In the past decade, the number of visibly tattooed footballers has greatly increased. Spectators were able to witness this continuing trend during the FIFA World Cup in Russia. Epidemiological studies have indicated that tattooed people are more risk-taking, extraverted and aggressive, but also more anxious and depressive than non-tattooed people [1-6]. It is unknown whether such personality traits reported in tattooed non-athlete populations may also apply to professional footballers, and if so whether this may have an impact on penalty success or not. Furthermore, it has been reported that seemingly insignificant visual cues play an important role for penalty outcomes. For example, the penalty taker's advance cues, kit colour, pre-penalty gaze and direction of vision can all influence the goalkeeper's performance $[7,8]$. Therefore, it is conceivable that tattoos of penalty takers may have a signal effect on goalkeepers as well. With this in mind we sought to analyse the effect of tattoos on penalty success.

\section{Methods}

All penalties taken during the FIFA World Cup 2018 were analysed. This included penalties taken during match play and those taken during penalty shoot-outs. Penalty takers were divided into "tattooed" and "non-tattooed" players according to their visible tattoos on their upper and lower extremities, and neck. To doublecheck, pictures of the penalty takers taken during the penalties were screened for (smaller) tattoos using Google "images." Thereafter, the penalty success rate was calculated for tattooed and nontattooed players. In addition to the overall penalty success rate, the success rate in penalty shoot-outs was compared separately as the personality traits may be exaggerated due to the heightened stress level. $\chi^{2}$ tests were performed to test the data against the null hypothesis that the probability of scoring does not depend on whether or not the penalty taker is tattooed.

\section{Results}

A total of 69 penalties were taken, 48 of which (69.56\%) were scored. Non-tattooed players took 44 penalties, and tattooed players took 25 (Table 1). The success rate of non-tattooed players was $68.18 \%(30 / 44)$, whereas the success rate of tattooed players was $72.00 \%(18 / 25)(p>0.05)$. In the knockout stages, the success rate in the penalty shoot-outs was $62.50 \%(17 / 24)$ in non-tattooed and $73.00 \%(11 / 15)$ in tattooed penalty takers $(p>0.05)$.

\section{Discussion}

Penalties and in particular shoot-outs are often termed a "lottery" [9]. However, in recent years, attempts have been made to better understand and explain their outcomes scientifically [1016]. It appears that many variables including kicking technique, visual search strategies, tactical skills and fitness contribute to the performance of penalty takers, alongside basic "chance" [17, 18]. However, psychological factors are reportedly the most influential determinant of penalty outcomes [14]. Visible tattoos may be of interest in this context for two reasons. Firstly, numerous publications have identified personality differences between tattooed and non-tattooed people [1-6], and these personality traits could affect the penalty taker's performance. Secondly, tattoos could possibly underline a dominant, self-confident appearance of the penalty taker, which could subconsciously intimidate the goalkeeper, like a modern "war paint." Although tattooed penalty takers had slightly higher success rates (particularly in shoot-outs) than the non-tattooed penalty takers, the null hypothesis was not rejected in our analysis. However, the power to detect a difference between tattooed and non-tattooed players in a $\chi^{2}$ test is very small with the current number of observations ( 69 penalties in total). Therefore, further analyses are needed to assess the impact of tattoos on penalty success. If scoring goals did indeed prove to be a tattoo "complication," it would certainly be one of the more welcome complications there are $[19,20]$.

\section{Key Message}

Tattoos may have an influence on penalty success.

Disclosure Statement

The authors declare no conflict of interest.
KARGER

(C) 2018 S. Karger AG, Basel 
Table 1. All penalties taken during the FIFA World Cup 2018 including the success rates of tattooed and non-tattooed penalty takers (overall success rate and success rate in the shoot-outs)

\begin{tabular}{|c|c|c|c|c|}
\hline & $\begin{array}{l}\text { Non-tattooed penalty } \\
\text { takers }\end{array}$ & $\begin{array}{l}\text { Penalty } \\
\text { success }\end{array}$ & Tattooed penalty takers & $\begin{array}{l}\text { Penalty } \\
\text { success }\end{array}$ \\
\hline Group phase & Salman Al-Faraj & 1 & Andreas Granqvist & 1 \\
\hline Group phase & Karim Ansarifard & 1 & Andreas Granqvist & 1 \\
\hline Group phase & Artem Dzyuba & 1 & Eden Hazard & 1 \\
\hline Group phase & Artem Dzyuba & 1 & Victor Moses & 1 \\
\hline Group phase & Mile Jedinak & 1 & Christian Cueva & 0 \\
\hline Group phase & Mile Jedinak & 1 & Lionel Messi & 0 \\
\hline Group phase & Shinji Kagawa & 1 & Bryan Ruiz & 0 \\
\hline Group phase & Harry Kane & 1 & Antoine Griezmann (long sleeves) & 1 \\
\hline Group phase & Harry Kane & 1 & Antoine Griezmann (long sleeves) & 1 \\
\hline Group phase & Luka Modric & 0 & & \\
\hline Group phase & Luka Modric & 1 & & \\
\hline Group phase & Christiano Ronaldo & 1 & & \\
\hline Group phase & Christiano Ronaldo & 0 & & \\
\hline Group phase & Mohamed Salah & 1 & & \\
\hline Group phase & Ferjani Sassi & 1 & & \\
\hline Group phase & Gylfi Sigurdsson & 1 & & \\
\hline Group phase & Gylfi Sigurdsson & 0 & & \\
\hline Group phase & Carlos Vela & 1 & & \\
\hline Group phase & Fahad Al-Muwallad & 0 & & \\
\hline Knockout phase, regular time & Luka Modric & 0 & Antoine Griezmann (long sleeves) & 1 \\
\hline Knockout phase, shoot-out & Andres Iniesta & 1 & Sergio Ramos & 1 \\
\hline Knockout phase, shoot-out & Gerard Pique & 1 & Iago Aspas & 0 \\
\hline Knockout phase, shoot-out & Koke & 0 & Fyodor Smolow & 1 \\
\hline Knockout phase, shoot-out & Sergey Ignashevich & 1 & Aleksandr Golovin & 1 \\
\hline Knockout phase, shoot-out & Denis Cheryshev & 1 & Ivan Rakitic & 1 \\
\hline Knockout phase, shoot-out & Luka Modric & 1 & Simon Kier & 1 \\
\hline Knockout phase, shoot-out & Milan Badelj & 0 & Lasse Schöne & 0 \\
\hline Knockout phase, shoot-out & Andrej Kramaric & 1 & Michael Krohn-Deli & 1 \\
\hline Knockout phase, shoot-out & Josip Pivaric & 0 & Marcus Rashford & 1 \\
\hline Knockout phase, shoot-out & Christian Eriksen & 0 & Kieran Trippier & 1 \\
\hline Knockout phase, shoot-out & Nicolai Joergensen & 0 & Mateus Uribe & 0 \\
\hline Knockout phase, shoot-out & Harry Kane & 1 & Fyodor Smolow & 0 \\
\hline Knockout phase, shoot-out & Harry Kane & 1 & Marcelo Brozovic & 1 \\
\hline Knockout phase, shoot-out & Jordan Hendersson & 0 & Domagoj Vida & 1 \\
\hline Knockout phase, shoot-out & Eric Dier & 1 & Ivan Rakitic & 1 \\
\hline Knockout phase, shoot-out & Carlos Bacca & 0 & & \\
\hline Knockout phase, shoot-out & 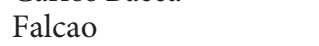 & 1 & & \\
\hline Knockout phase, shoot-out & Juan Cuadrado & 1 & & \\
\hline Knockout phase, shoot-out & Alan Dzagoev & 1 & & \\
\hline Knockout phase, shoot-out & Matteo Kovacic & 0 & & \\
\hline Knockout phase, shoot-out & Mario Fernandes & 0 & & \\
\hline Knockout phase, shoot-out & Luka Modric & 1 & & \\
\hline Knockout phase, shoot-out & Sergey Ignashevich & 1 & & \\
\hline Knockout phase, shoot-out & Daler Kuzyayev & 1 & & \\
\hline Total & & 44 & & 25 \\
\hline Overall success rate, $\%$ & & $68.18(30 / 44)$ & & $72.00(18 / 25)$ \\
\hline Success rate in the shoot-outs, $\%$ & & $62.50(15 / 24)$ & & $73.33(11 / 15)$ \\
\hline
\end{tabular}




\section{References}

1 Kluger N: Epidemiology of tattoos in industrialized countries. Curr Probl Dermatol 2015;48:6-20.

2 Carroll ST, Riffenburgh RH, Roberts TA, Myhre EB: Tattoos and body piercings as indicators of adolescent risk-taking behaviors. Pediatrics 2002;109:1021-1027.

3 Heywood W, Patrick K, Smith AM, Simpson JM, Pitts MK, Richters J, Shelley JM: Who gets tattoos? Demographic and behavioral correlates of ever being tattooed in a representative sample of men and women. Ann Epidemiol 2012;22:51-56.

4 Roberts TA, Ryan SA: Tattooing and high-risk behavior in adolescents. Pediatrics 2002;110:1058-1063.

5 Zrno M, Frencl M, Degmecic D, Pozgain I: Emotional profile and risk behaviours among tattooed and non-tattooed students. Med Glas (Zenica) 2015;12:93-98.

6 Swami V, Pietschnig J, Bertl B, Nader IW, Stieger S, Voracek M: Personality differences between tattooed and non-tattooed individuals. Psychol Rep 2012;111:97-106.

7 Greenlees I, Leyland A, Thelwell R, Filby W: Soccer penalty takers' uniform colour and pre-penalty kick gaze affect the impressions formed of them by opposing goalkeepers. J Sports Sci 2008;26:569-576.

8 Nunez FJ, Ono A, Raya A, Bilbao A: Effects of providing advance cues during a soccer penalty kick on the kicker's rate of success. Percept Motor Skills 2010;111:749-760.

9 Wood G, Jordet G, Wilson MR: On winning the "lottery": psychological preparation for football penalty shoot-outs. J Sports Sci 2015;33:1758 1765.

10 Greenlees IA, Eynon M, Thelwell RC: Color of soccer goalkeepers' uniforms influences the outcome of penalty kicks. Percept Motor Skills 2013;117:1043-1052.
11 Misirlisoy E, Haggard P: Asymmetric predictability and cognitive competition in football penalty shootouts. Curr Biol 2014;24:1918-1922.

12 Furley P, Noel B, Memmert D: Attention towards the goalkeeper and distraction during penalty shootouts in association football: a retrospective analysis of penalty shootouts from 1984 to 2012. J Sports Sci 2017; 35:873-879.

13 Braun S, Schmidt U: The gambler's fallacy in penalty shootouts. Curr Biol 2015;25:R597-R598.

14 Jordet G, Hartman E, Visscher C, Lemmink KA: Kicks from the penalty mark in soccer: the roles of stress, skill, and fatigue for kick outcomes. J Sports Sci 2007;25:121-129.

15 Moll T, Jordet G, Pepping GJ: Emotional contagion in soccer penalty shootouts: Celebration of individual success is associated with ultimate team success. J Sports Sci 2010;28:983-992.

16 Jordet G: Why do English players fail in soccer penalty shootouts? A study of team status, self-regulation, and choking under pressure. J Sports Sci 2009;27:97-106.

17 Timmis MA, Turner K, van Paridon KN: Visual search strategies of soccer players executing a power vs placement penalty kick. PLoS One 2014; 9:e115179.

18 Peiyong Z, Inomata K: Cognitive strategies for goalkeeper responding to soccer penalty kick. Percept Motor Skills 2012;115:969-983.

19 Serup J, Sepehri M, Hutton Carlsen K: Classification of tattoo complications in a hospital material of 493 adverse events. Dermatology 2016;232: 668-678.

20 Kluger N: Cutaneous complications related to tattoos: 31 cases from Finland. Dermatology 2017;233:100-109. 